\title{
THE AIR FLOW INFLUENCE ON THE DRAG FORCE OF A SPORTS CAR
}

\author{
Zbigniew Czyż', Paweł Karpiński', Michał Gęca', Jacobo Ulibarrena Diaz ${ }^{2}$ \\ 1 Lublin University of Technology, Faculty of Mechanical Engineering, Department of Thermodynamics, Fluid \\ Mechanics and Aviation Propulsion Systems, Nadbystrzycka 36 Str., 20-618 Lublin, Poland, e-mail: z.czyz@ \\ pollub.pl \\ 2 University of a Coruña, Higher Polytechnic University College, Mendizábal Str., s/n., 15403 Ferrol, Spain
}

Received: 2017.12.29

Accepted: 2018.03.04

Published: 2018.06.01

\begin{abstract}
ABSTARCT
The paper presents the numerical analysis of the drag force generated on the body of a sports car, based on the CFD method in the Ansys Fluent program. The three-dimensional model of the vehicle was taken from an open CAD database. Based on this, a computational grid was developed, boundary conditions and a turbulence model were defined. As a result of the calculations, the pressure distribution on the individual body parts and the velocity distribution in selected cross sections were obtained. In the next part of the research, the simulation results are used to optimize the shape of the bodywork of different passenger vehicles in order to reduce the generated drag force.
\end{abstract}

Keywords: numerical analysis, CFD, drag force, car body, sports car.

\section{INTRODUCTION}

According to the report of The International Council on Clean Transportation - ICCT, over the past 10 years the share of sports cars in the passenger car market in the EU has remained at a relatively constant level (below $0.5 \%$ ) [1]. However, many technical solutions used in sports cars are used in the design and production of cars from other segments. An example of this type of procedure is the implementation of the aerodynamic shape of the bodywork and its components from sports cars to city cars. By optimizing the geometry of the bodywork, it is possible to reduce the aerodynamic drag force. This results in reduced fuel consumption, which causes lower emission of toxic substances. In addition, lower aerodynamic drag also affects the vehicle's acceleration and maximum speed.

The total drag force $\mathrm{P}_{\mathrm{x}}$ produced on the vehicle body is given by (1):

$$
P_{x}=0.5 \cdot \rho \cdot v^{2} \cdot S \cdot C_{x}
$$

where: $\rho$ - density, $\mathrm{v}$ - velocity, $\mathrm{S}$ - frontal area of the body car, $\mathrm{C}_{\mathrm{x}}$ - drag coefficient.
The drag coefficient is related to the shape of the bodywork (its aerodynamics shape) and does not reflect to the actual effect of the drag force generated on the bodywork. Therefore, it is more convenient to compare the product of the drag coefficient $\mathrm{C}_{\mathrm{x}}$ and the frontal area of the body car $\mathrm{S}$ [2].

In sports cars, the drag force plays a significant role in aerodynamics. Moreover, the value of negative lift force $\mathrm{P}_{\mathrm{z}}$ is important because it influences vehicle downforce, stability and driving characteristics.

The CFD (Computational Fluid Dynamics) method is a popular and accurate method of researching aerodynamics of vehicles. This is a numerical method based on the discretization of the studied area and the solving of partial differential equations characterizing the flow around the examined object. As a result of calculations, the pressure, velocity and temperature distribution in the flow is obtained.

The aerodynamic study of a racing car using this method is presented in [3]. The work focused on improving the stability of the vehicle and reducing the force generated on the body. The re- 
sults of the research were presented in the form of calculated pressure and velocity contours. Moreover, the coefficient of aerodynamic drag force was calculated.

The aerodynamic analysis of the air flow around the vehicle can also be used to determine the location of test and measurement devices. In the paper [4], the authors analysed the air flow around the vehicle, concentrating mainly on the air velocity field in order to properly locate the research object in the form of a gyroplane model. The analysis of the air velocity field allowed them to identify the area with no interference between the test object and the object used to create an air flow (vehicle).

Drag can be reduced by reducing the coefficient of resistance and thus by modifying the vehicle's body shape. An example of such an approach is presented in the work [5] where the effect of changing the rear under body shape on the drag coefficient was calculated. The tilt angle of the rear under body part in relation to the ground plane was changed.

A numerical analysis of a flow can be carried out on a precise or simplified geometric model. The Ahmed's body is a commonly used model for aerodynamic studies of vehicles. It is a simplified body with defined dimensions. Such a geometrical model was used in the study of drag force in the works [6] and [7].

An experimental validation of numerical results can be carried out using a wind tunnel. It is also possible to use the PIV (Particle Image Velocimetry) method to research an air flow on a vehicle model on a test bench. In the study [8] the research of the aerodynamics of the bus model using a DPIV digital technique was performed. The vector maps of the velocities and swirls for selected planes were determined; and the streamlines and selected parameters of a turbulence flow were obtained.

It is important to adopt an appropriate turbulence model during an aerodynamic analysis of a body structure. A turbulence model widely used for simulating aerodynamics of vehicles is a k- $\omega$ model. However, in the case of simplified calculations, it is possible to use a k- $\varepsilon$ model as shown in the work [9] in the study of the aerodynamic drag force of a passenger car model. The drag force coefficient obtained in these calculations only slightly, i.e. about $7 \%$ differed from the experimental coefficient. This confirms the accuracy of the defined model.
One of the method of improving vehicle's aerodynamics without affecting the body structure is using additional components for the body such as a flap or a spoiler. In the study [10], a vehicle equipped with a spoiler was investigated with the use of CFD method. The influence of the spoiler angle set on the generated drag and lift forces was investigated.

Another additional features which improve vehicle's aerodynamics are additional trailing edges attached at an angle to the roof or the rear bumper. The numerical analysis based on this type of body was carried out in the publication [11]. The research showed that the presence of additional tail plates results in a reduction in the generated drag and lift forces.

\section{RESEARCH OBJECT}

The research object is a solid model of the sports car retrieved from the open database GrabCAD [12]. The model was imported into the Design Modeler in the Ansys. Its position relative to the global coordinate system is shown in Fig.

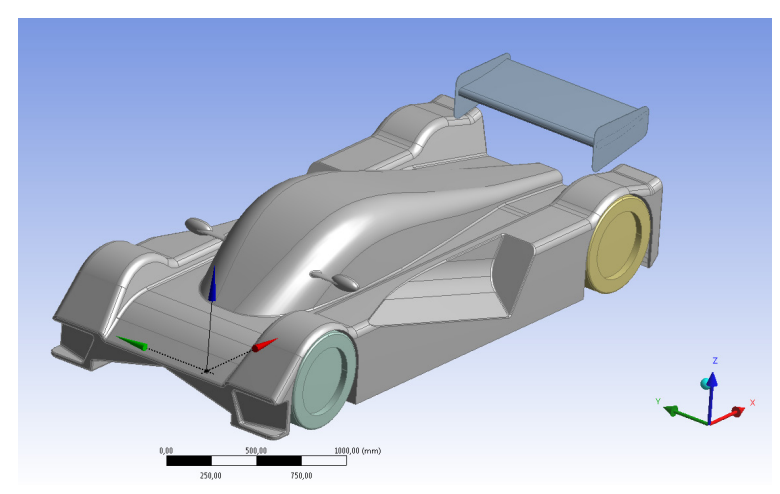

Fig. 1. The solid model of the vehicle with the assumed coordinate system

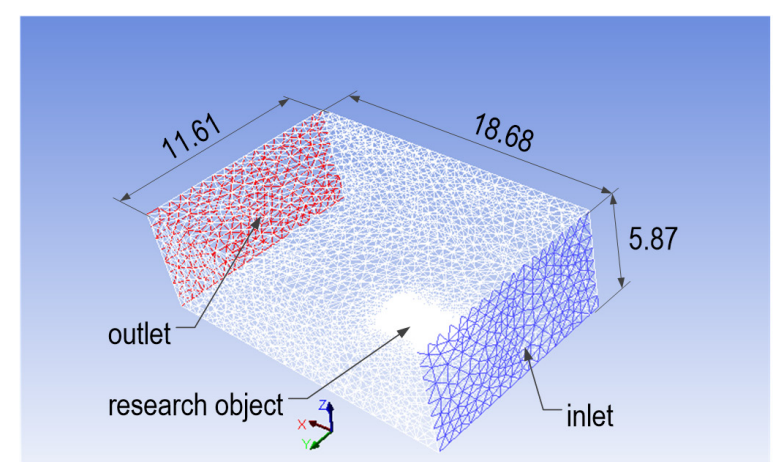

Fig. 2. Computational domain of the vehicle 

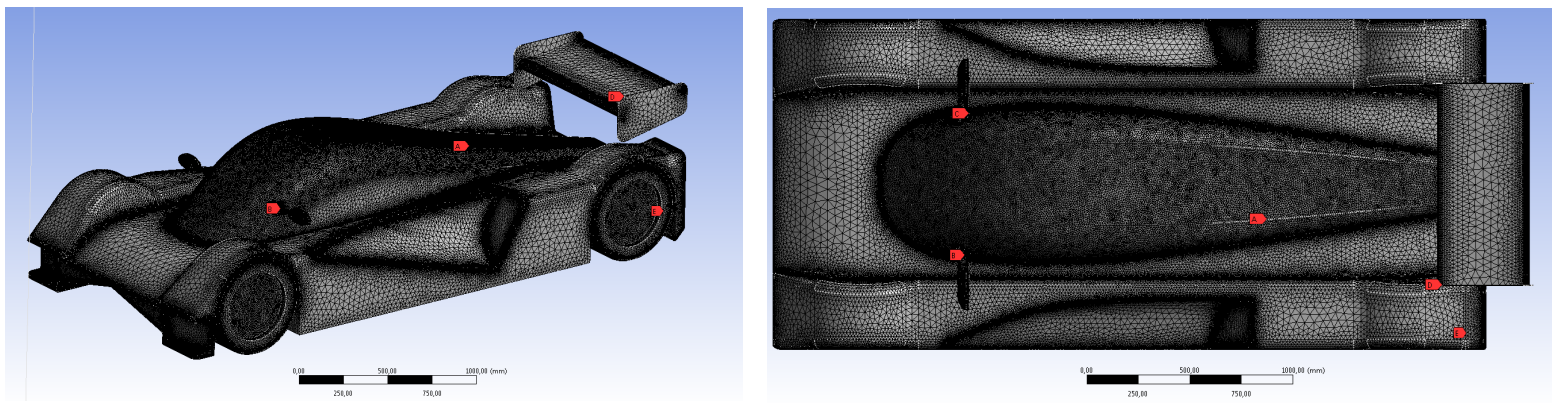

Fig. 3. Generated computational grid with the selected body elements set as a wall type in the program: a roof - A, mirrors - B, a bodywork - C, a spoiler - D

1. The following axes are marked: $x$ - longitudinal axis (opposite to the driving direction), $y$ - axial axis (parallel to the road surface), $z$ - vertical axis (normal to the road surface). The dimensions of the model are $3.68 \times 0.87 \times 1.61 \mathrm{~m}$ (length $\mathrm{x}$ height $\mathrm{x}$ width).

The computational domain (Fig. 2) has the following dimensions: $18.68 \times 5.87$ x $11.61 \mathrm{~m}$ (length $\mathrm{x}$ height $\mathrm{x}$ width). For such a defined domain the inlet (front of the car), the outlet (rear of the car) and the research object as a wall type were set.

For this situation a computational grid of 2 647653 elements was generated. The grid consists of tet 4 , wed 6 and pyr5 elements. The body of the research vehicle is divided into four basic components: mirrors, a roof, a spoiler, a bodywork (Fig. 3).

The calculation was was a pressure based type. The simulation was performed under steady state conditions. The medium was assumed to be the ideal gas of a temperature of $15^{\circ} \mathrm{C}$ and a viscosity of $1.7894 \cdot 10^{-5}[\mathrm{~kg} \cdot \mathrm{m}-1 \mathrm{~s}-1]$. A k- $\omega$ SST model was adopted as a model of turbulence. This model forms better the turbulent flow in the boundary layer and is very sensitive to the value of the size of the free turbulent flow. SST means that there is a limitation of the main stresses value in the flow. The k- $\omega$ SST combines the advantages of $k-\varepsilon$ and $k-\omega$.

It is possible to use a $\mathrm{k}-\varepsilon$ model for simplified aerodynamic calculations. This widely used in engineering calculations model is based on two equations that characterize turbulence in the flow. The first equation defines the kinetic energy of turbulence $\mathrm{k}$, and the second defines the turbulent kinetic energy dissipation $\varepsilon$.

Moreover, a turbulence length scale parameter can be defined. It is useful for describing a turbulence phenomenon. It determines the size of large eddies carrying energy in the turbulent flow.
For the fully developed flow through the duct, size 1 is determined by the size of the duct because the turbulent eddies cannot be larger than the duct size. The approximated relationship between size 1 and the physical size of the duct is as follows (2):

$$
\boldsymbol{l}=0.07 L
$$

where: $\mathrm{L}$ - the reference length related to the size of the duct.

In order to take into account the turbulence effects, a turbulent intensity equal to $5 \%$ and a turbulent length scale equal to $0.81 \mathrm{~m}$ for the inlet and outlet were determined.

For such a defined model, a series of simulations were performed, depending on the velocity of the air flow. The computational cases for the simulations are: $\mathrm{v}=13,30,60,90 \mathrm{~m} / \mathrm{s}$. For the last computational case, it was necessary to change the type of calculation to a density-based one due to the influence of a compressibility effect on the results obtained.

\section{RESULTS}

As a result of the calculations, the pressure and speed contours on the body of the test vehicle were obtained for four computational cases. The views of the selected contours are shown in Fig. 4, Fig. 5 and Fig. 6.

In addition, the drag forces of the individual components of the car body were obtained (Table 1).

Based on the results obtained, a scatter plot of the total drag force was drawn as a function of air velocity. For these points, a second-order polynomial trend line (Fig. 7) was determined with the equation (3):

$$
P_{x}=0.318 v^{2}-0.2439 v+7.1378
$$

The column diagrams showing the value of the drag forces generated on the individual body 


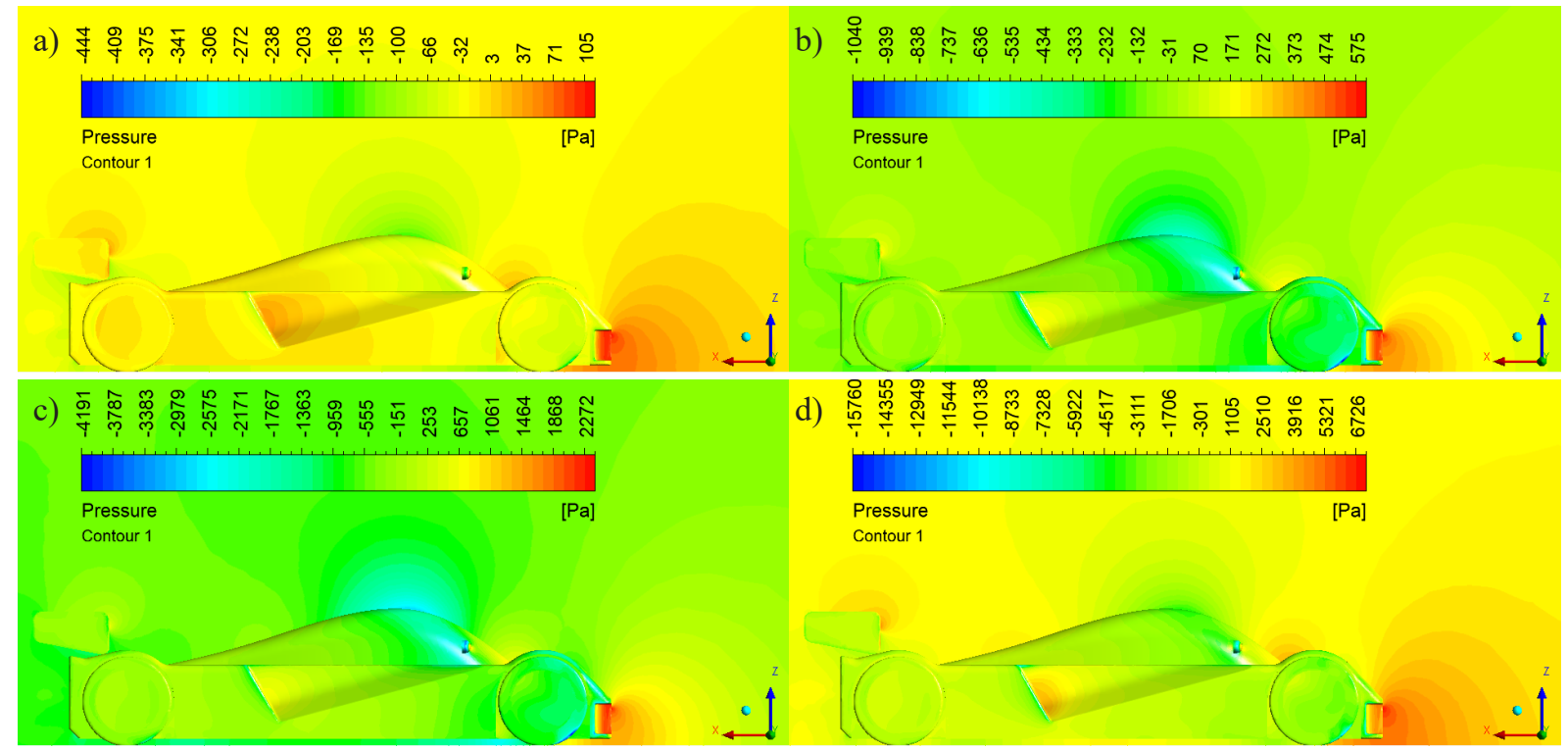

Fig. 4. The pressure contours on the body of the test vehicle in an isometric view for the air velocity v equal to: a) $13 \mathrm{~m} / \mathrm{s}$, b) $30 \mathrm{~m} / \mathrm{s}$, c) $60 \mathrm{~m} / \mathrm{s}$, d) $90 \mathrm{~m} / \mathrm{s}$

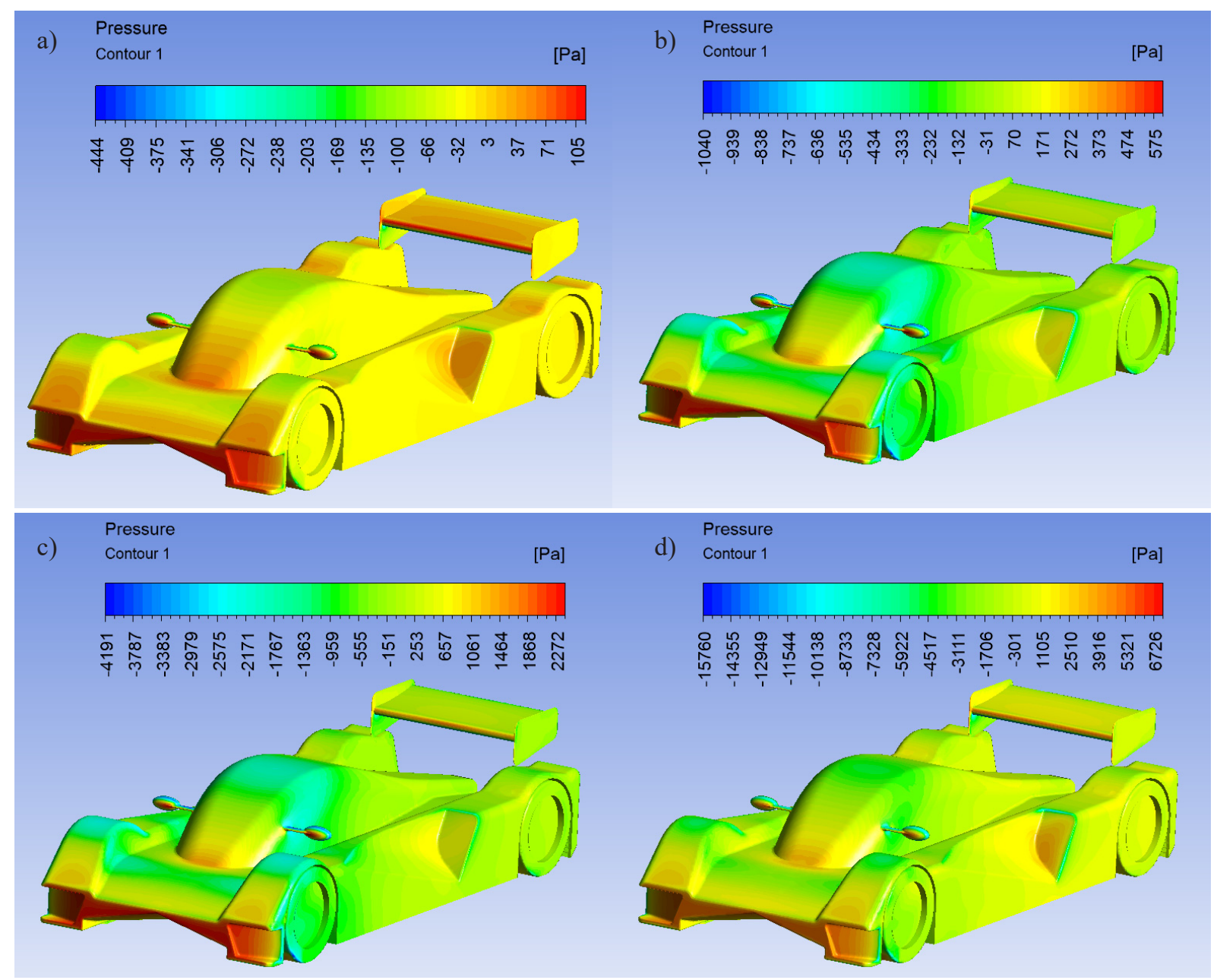

Fig. 5. The pressure contours on the body of the test vehicle in an isometric view for the air velocity $\mathrm{v}$ equal to: a) $13 \mathrm{~m} / \mathrm{s}$, b) $30 \mathrm{~m} / \mathrm{s}$, c) $60 \mathrm{~m} / \mathrm{s}$, d) $90 \mathrm{~m} / \mathrm{s}$ 


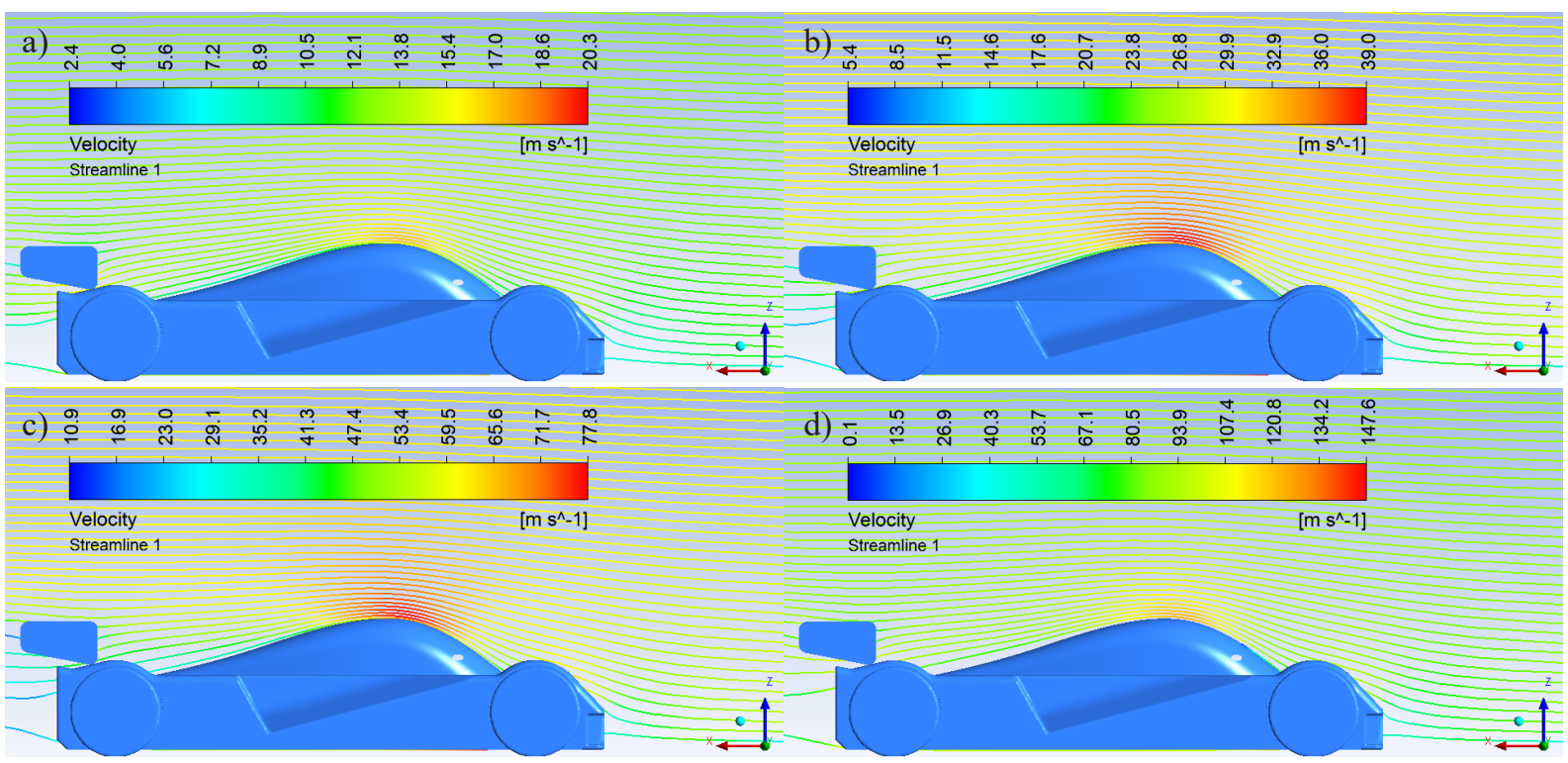

Fig. 6. The velocity contours on the body of the test vehicle in an isometric view for the air velocity $\mathrm{v}$ equal to: a) $13 \mathrm{~m} / \mathrm{s}$, b) $30 \mathrm{~m} / \mathrm{s}$, c) $60 \mathrm{~m} / \mathrm{s}$, d) $90 \mathrm{~m} / \mathrm{s}$

parts in relation to the air velocity are presented in Figure 8.

\section{DISCUSSION AND CONCLUSIONS}

Based on the pressure contours on the symmetrical plane, it was found that the extreme pressure values should be read on the belt in the front of the bodywork. The maximum value of overpressure at a flow velocity of $13 \mathrm{~m} / \mathrm{s}$ is relatively small at $105 \mathrm{~Pa}$ and increases with increasing velocity, resulting in the values of $575 \mathrm{~Pa}, 2272$ $\mathrm{Pa}$ and $6726 \mathrm{~Pa}$, respectively for the subsequent airflow velocities. The pressure increase occurs on the leading edge of the spoiler and on the flat surface located in front of the rear wheel arches.

The highest absolute value of vacuum is generated in the zone above the cabin. According to Bernoulli's principle, there is a negative pressure caused by acceleration on the rounded profile on the roof of the car body. The values of the vacuum

Table 1. Generated drag force on a car body

\begin{tabular}{|c|c|c|c|c|}
\hline Computational case & Name & Velocity $v(\mathrm{~m} / \mathrm{s})$ & Drag force $(\mathrm{N})$ & Total drag force $P_{x}(N)$ \\
\hline \multirow{4}{*}{1} & Bodywork & \multirow{4}{*}{13} & 56.577 & \multirow{4}{*}{63.860} \\
\hline & Spoiler & & 5.022 & \\
\hline & Mirrors & & 1.408 & \\
\hline & Roof & & 0.853 & \\
\hline \multirow{4}{*}{2} & Bodywork & \multirow{4}{*}{30} & 272.207 & \multirow{4}{*}{295.114} \\
\hline & Spoiler & & 21.390 & \\
\hline & Mirrors & & 7.141 & \\
\hline & Roof & & -5.624 & \\
\hline \multirow{4}{*}{3} & Bodywork & \multirow{4}{*}{60} & 1048.79 & \multirow{4}{*}{1124.963} \\
\hline & Spoiler & & 73.401 & \\
\hline & Mirrors & & 27.789 & \\
\hline & Roof & & -25.017 & \\
\hline \multirow{4}{*}{4} & Bodywork & \multirow{4}{*}{90} & 2398.7 & \multirow{4}{*}{2565.702} \\
\hline & Spoiler & & 183.922 & \\
\hline & Mirrors & & 44.360 & \\
\hline & Roof & & -61.280 & \\
\hline
\end{tabular}




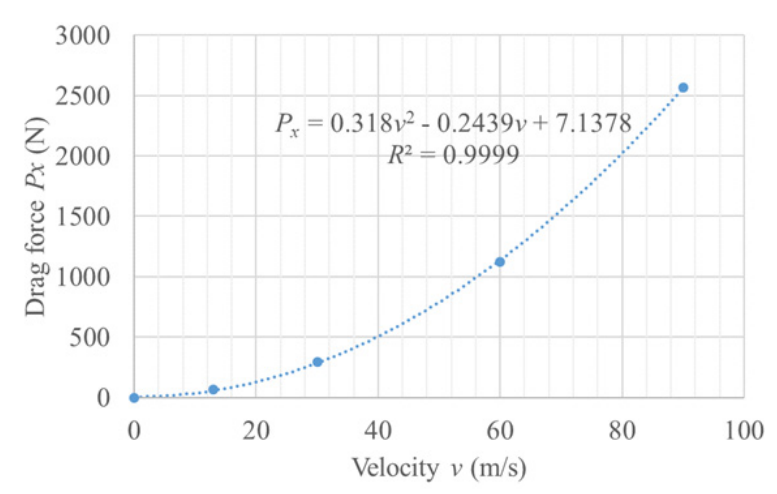

Fig. 7. Total drag force as a function of air velocity

generated on the roof of the research vehicle are about $170 \mathrm{~Pa}$ at a flow rate of $13 \mathrm{~m} / \mathrm{s}$ and, respectively, $640 \mathrm{~Pa}, 2500 \mathrm{~Pa}$ and $4500 \mathrm{~Pa}$ for the subsequent research speeds.

The extreme values of speed occur in places of a reduced pressure, i.e. above the cabin and the front wheel arches. The maximum values of air velocity in the plane of symmetry are respectively $20.3 \mathrm{~m} / \mathrm{s}, 39.0 \mathrm{~m} / \mathrm{s}, 77.8 \mathrm{~m} / \mathrm{s}, 147.6 \mathrm{~m} / \mathrm{s}$ for the each computational case. This represents an increase in velocity from $30 \%$ to $64 \%$ with respect to the value of the velocity of the undisturbed flow.

The greatest contribution to the generation of aerodynamic drag force is the bodywork. The component of the drag force generated on the spoiler, mirrors and the roof is ten times lower (Fig. 8). In addition, a negative drag force equal to $30 \mathrm{~m} / \mathrm{s}$ is generated at the roof.

Based on the analysis of the results obtained, attention should be paid to the formation of vacuum areas above and below the vehicle, which is a characteristic feature of sports cars. At the rear of the car, there is a very small vacuum field with lower

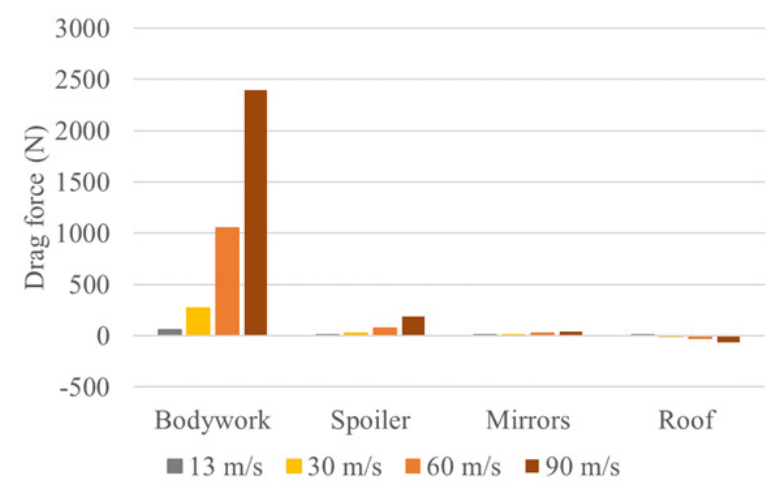

absolute values compared to the one in typical passenger cars, especially with respect to vehicles with a rectangular geometry such as buses and trucks.

The performed calculations can be used to optimize the shape of the vehicle or to investigate the impact of additional components on the bodywork (for example changing the profile and tilt angle of the spoiler, using additional flaps and fairings) to the general aerodynamic characteristics.

\section{NOMENCLATURE}

$\mathrm{C}_{\mathrm{x}}-$ drag force coefficient [-]

$\mathrm{L}$ - the reference length related to the size of the duct, $[\mathrm{m}]$

1 -turbulence length scale, [m]

$\mathrm{P}_{\mathrm{x}}$ - drag force, [N]

$\mathrm{S}$ - frontal area of the body car, $\left[\mathrm{m}^{2}\right]$

$\mathrm{v}$ - velocity, $[\mathrm{m} / \mathrm{s}]$

$\rho$ - density, $\left[\mathrm{kg} / \mathrm{m}^{3}\right]$

\section{REFERENCES}

1. The International Council on Clean Transportation, European Vehicle Market Statistics 2016/2017.

2. Guiggiani, M., The Science of Vehicle Dynamics: Handling, Braking, and Ride of Road and Race Cars, Springer, 2014.

3. Hetawal, S., et al., Aerodynamic study of formula SAE car, Procedia Engineering, 97, 2014, 1198-1207.

4. Czyż, Z., et al., Experimental investigation of the impact of flight speed on drag force in the autogyro model, Advances in Science and Technology Research Journal, 9 (2015), 26, pp. 89-95.

5. Rakibul Hassan, S. M., et al., Numerical study on aerodynamic drag reduction of racing cars, Procedia Engineering, 90 (2014), pp. 308-313.

6. Roumeas, M., et al., Drag reduction by flow separation control on a car after body, International Journal for Numerical Methods in Fluids, 60, 2009, 1222-1240.

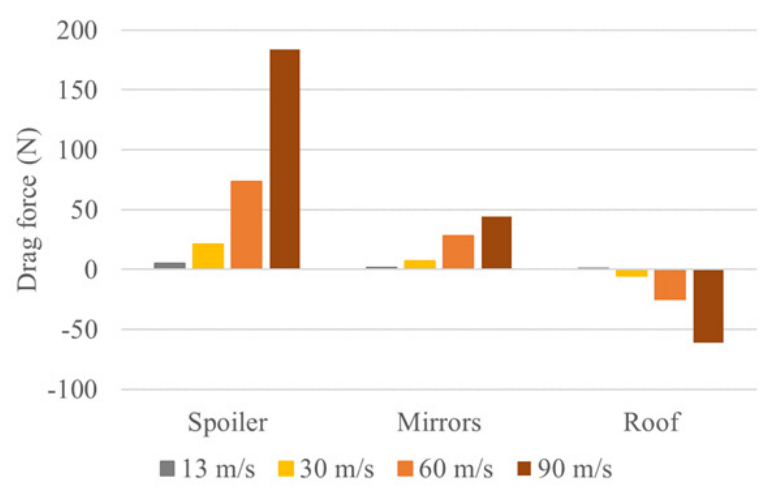

Fig. 8. Drag forces for individual components of the car body depending on the air velocity 
7. Bello-Millan, F. J., et al., Experimental study on Ahmed's body drag coefficient for different yaw angles, Journal of Wind Engineering and Industrial Aerodynamics, 157 (2016), pp. 140-144.

8. Gurlek, C., et al., PIV studies around a bus model, Experimental Thermal and Fluid Science, 38, 2012, 115-126.

9. Ponnusamy Nallusamy, S., Kanjikovil Mahali, P., Numerical and experimental investigations of drag force on scaled car model, Thermal Science, 20, 2016, 1153-1158.

10. Das, R. C., Riyad, M., CFD analysis of passenger vehicleat various angle of rear end spoiler, Procedia Engineering, 194 (2017), pp. 160-165.

11. Sharma, R. B., Bansal, R., CFD simulation for flow over passenger car using tail plates for aerodynamic drag reduction, Journal of Mechanical and Civil Engineering, 7, 2013, 28-35.

12. Database grabcad.com 